\title{
LA PRESENCIA DEL PORTUGUÉS EN PRENSA ESCRITA URUGUAYA: CÓMO EL MUNDIAL 2014 NOS SOLTÓ LA PLUMA
}

\author{
Mayte Gorrostorrazo 1 \\ ${ }^{1}$ Universidad de la República, Montevideo, Uruguay \\ Rosario Lázaro Igoa 2 \\ ${ }_{2}^{2}$ Universidade de Santa Catarina, Florianópolis, Santa Catarina, Brasil \\ Leticia Lorier ${ }^{3}$ \\ ${ }^{3}$ Universidad de la República, Montevideo,Uruguay
}

Resumen: Este trabajo aborda el uso del portugués en la prensa escrita uruguaya durante el Mundial de Fútbol 2014 desde los Estudios de Traducción, la Lingüística y la Comunicación. Para el análisis del corpus, compuesto por las ediciones del periódico la diaria del período entre el 01 de junio y el 15 de julio de 2014, se usa el concepto de extranjerismo como procedimiento en el que existe una operación traductiva (BARBOSA, 1990). La sistematización se basa en la clasificación de los extranjerismos según características lingüísticas, el contexto de uso y la relación con la lengua de llegada, en función de la clasificación de transferencias de Barbosa (1990). Los resultados indican que la recurrencia al portugués tiene un objetivo retórico, en ocasiones humorístico, y se vincula con representaciones sobre lo brasilero (PAGANOTTI, 2007) y con la percepción del portugués como lengua inteligible para el hablante de español.

Palabras clave: Traducción; Escritura periodística; Prensa uruguaya; Extranjerismos. Portugués. 


\title{
THE PRESENCE OF PORTUGUESE IN URUGUAYAN PRESS: HOW THE WORLD CUP 2014 LOOSENED UP OUR WRITING
}

\begin{abstract}
This paper addresses the use of Portuguese in the Uruguayan press during the 2014 World Cup from the point of view of Translation Studies, Linguistics and Communication Studies. For the analysis of the corpus, built of the editions of la diaria newspaper between June 1st and July 15th, 2014, we use the concept of foreignism as a procedure in which there is a translation operation (BARBOSA, 1990). The systematization is based on the classification of foreignisms according to linguistic characteristics, the context of use and its relation with the target language, according to Barbosa classification of transfers (1990). The results suggest that the recurrence to Portuguese has a rhetorical objective, sometimes humorous and associated to the representations of Brazil (PAGANOTTI, 2007) and to the perception of Portuguese as intelligible for the Spanish speaker.
\end{abstract}

Keywords: Translation; Journalistic writing; Uruguayan press; Foreignisms; Portuguese.

\section{Introducción}

Distintos abordajes de la prensa por parte de los Estudios de la Traducción (CONWAY y BASSNETT 2006; BIELSA y BASSNETT 2009; HERNÁNDEZ GUERRERO 2009) sugieren que en la traducción de noticias no siempre es posible establecer cuál fue el texto original traducido, al tiempo que es frecuente la acción de transediting (STETTING 1989, p. 377). La confluencia de traducción y edición en una misma acción determina que los artículos no siempre sean fruto de un procedimiento de traducción en sentido estricto, además de poner en jaque la autoría del texto. Asimismo, existen géneros periodísticos, como veremos en este trabajo, en los que la introducción de palabras o expresiones extranjeras se orienta más por razones estilísticas que por necesidades de la traducción interlingüística. A pesar de la relevancia de las investigaciones citadas, la discusión sobre la traducción 
es casi inexistente en el ámbito del periodismo, como demuestra Roberto Valdeón (2017) en un artículo reciente.

El Mundial de Fútbol 2014 en Brasil generó en la prensa uruguaya noticias provenientes de dicho país, ya sea por los acontecimientos deportivos, ya sea por hechos políticos y sociales importantes que ocurrieron mientras se llevó a cabo el evento deportivo. En consecuencia, la prensa uruguaya estuvo más en contacto con el portugués, lengua con la cual el español tiene similitudes evidentes, pero también diferencias notables. Aunque la noticia deportiva era el género textual más esperable, producto del desplazamiento de periodistas uruguayos a Brasil para cubrir el evento, en otras secciones del periódico el portugués tuvo también una presencia constatable durante ese período. El fenómeno resulta de interés por la introducción de palabras y expresiones propias del portugués en el discurso periodístico en español, que en ocasiones puede relacionarse con ciertos estereotipos de lo brasilero. Al respecto, Ivan Paganotti (2007, p. 7) propuso cuatro categorías (de plástico, de barro, sangriento y verde) para las formas estereotipadas en que es representado Brasil en coberturas internacionales.

El concepto de extranjerismo ${ }^{1}$ que subyace a este estudio proviene del campo de los Estudios de la Traducción: no nos referiremos al fenómeno del préstamo lingüístico, ni a palabras propias del español del Uruguay cuyos orígenes se remontan al portugués de Brasil. En este trabajo, el extranjerismo será la "palabra que una lengua [el español] toma de otra [el portugués] sin traducir” (García Yebra 1984, p.333), definición también apoyada por Barbosa $(1990$, p.72). Si bien una de las razones para que exista préstamo es precisamente la ausencia de una determinada palabra en la lengua receptora o meta "generalmente relacionada con una técnica nueva, con un concepto desconocido entre los hablantes de esta lengua” (GARCÍA YEBRA 1984, p. 334), por ejemplo, la palabra

\footnotetext{
${ }^{1}$ Preferimos el uso del término extranjerismo al de préstamo, siguiendo a Barbosa (1990, p. 72-73), pero respetamos el término préstamo cuando es el preferido por los autores citados.
} 
caipiriña, tomada del portugués y hoy diccionarizada en español, este motivo no era suficiente para explicar la proliferación del portugués en la prensa durante el período estudiado.

Así, en un relevamiento inicial no exhaustivo, fue posible observar la presencia del portugués en diferentes medios durante el Mundial 2014, como se muestra en los siguientes ejemplos de la prensa digital:

1. Además, ratificó que éste es un equipo cortado por la tijera de Scolari: pragmático, que no es ni pariente lejano de los de la familia del "jogo bonito" [...] (Ovación digital, 13/06/2014, s. p.).

2. [...] "vergonha" en la prensa brasileña. (La República, 09/07/2014, s. p.).

3. "Vergonhazo", "Salchichazo" y "Humillación", en las tapas tras el 7-1 (El Observador, 09/07/2014, s. p.).

4. Parte de la "torcida" ya se había ido, desolada, amargada, destruída... Fue un Mineirazo. Alemania, "vocé abusou" [...] (Ovación, 09/07/2014, s. p.). ${ }^{2}$

\section{Objetivo y marco teórico}

El presente trabajo analiza la presencia del portugués en la prensa escrita y su uso como recurso retórico en la redacción periodística, más precisamente en el periódico la diaria. El corpus observado está constituido por las ediciones correspondientes al período entre el 01 de junio y el 15 de julio de 2014. Vale especificar que no dejamos de lado la preexistencia de palabras de origen portugués ya incorporadas en el español del Uruguay ni tampoco la evidencia de un movimiento traductivo cuando fuera constatable.

Con tal objetivo, utilizamos un marco teórico que permitiera el abordaje de los extranjerismos no como fenómeno estrictamente

${ }^{2}$ El destacado en negrita es nuestro. 
lingüístico ni tampoco traductivo, sino como una intersección entre ambos. Como ya fue mencionado, no trabajamos con el extranjerismo una vez incorporado, el elemento, generalmente léxico, que una lengua toma de otra y que pasa a ser ampliamente aceptado por los hablantes de la primera, en la mayor parte de los casos, después de transitar por un proceso de adaptación morfofonológica (CÂMARA JUNIOR citado en BARBOSA 1990, p. 72). En este trabajo, el foco está puesto en la introducción de elementos léxicos y sintagmáticos provenientes del portugués como recurso retórico del discurso periodístico. Tal como propone Barbosa (1990, p. 9899), el empleo de este procedimiento puede estar relacionado con el hecho de considerar importante la explicitación de elementos de la lengua de partida en el texto de llegada para lograr fines estilísticos.

Recordemos que ya Quintiliano (1916a), en las Instituciones oratorias, sugería el uso moderado de barbarismos, que le darían "majestad" a la oratoria cuando usados en dosis justas. Sin embargo, el exceso amenazaría la inteligibilidad: “¡Cuán viciosa será la oración, cuya principal virtud es la claridad, si necesita de intérprete!" (QUINTILIANO 1916a, p. 35), advertía. A pesar de la máxima sobre el uso retórico de este tipo de palabras - "no parece fuera de propósito el advertir que no deben ser ni bárbaras ni extrañas" (QUINTILIANO 1916b, p. 29)—, sabemos que la aceptación y el prestigio de los extranjerismos varía según géneros discursivos y momentos históricos.

Vladimir Ivir (1998) indica que el préstamo (borrowing) resalta la extranjeridad del texto traducido, en tanto pone en evidencia lo que le falta a la lengua meta. Por esta razón, su uso respondería a una estrategia de poner la cultura en foco (IVIR 1998, p. 138), tensionar en el seno del texto traducido los términos en uso por esta nueva presencia. Ivir destaca, asimismo, que el fenómeno ocurriría dadas ciertas condiciones, como la necesaria relevancia del término en el texto, su papel preponderante cuando es comparado con otros términos en ese universo textual que lo harían digno de aparecer como tal. Advierte que un alto número de préstamos no terminarían de ser absorbidos por el lector (IVIR 1998, p. 139), aunque 
esta receptividad variaría según la "tradición de traducción" en cada comunidad de lectores (IVIR 1998, p. 140).

Es útil destacar dos puntos más introducidos por Ivir, que son significativos para este trabajo: el aspecto lingüístico sería un elemento de peso en el préstamo, se desprendería de esto que a mayor complejidad de las construcciones, menor frecuencia de préstamos; y que el préstamo no ocurriría cuando ambas lenguas compartieran términos con significados que se superponen (IVIR 1998, p. 141). Es más, de acuerdo a esa complejidad, el préstamo sería evitado o aparecería combinado con otras estrategias, como la explicación.

En suma, proponemos entender aquí el préstamo no como aquella "negación de la traducción" que condenaba Vinay (citado en BARBOSA, 1990, p. 26), sino como procedimiento en el que sí existe una operación traductiva, aunque implique introducir un término o un sintagma en lengua extranjera. Asimismo, como apunta Francis Aubert, el préstamo "no puede ser evaluado apenas de manera puntual, en el entorno cotextual inmediato de su ocurrencia" (AUBERT, 2003, p. 40), sino en relación con la totalidad del texto traducido. Para este trabajo, la relación es establecida con los textos y también con las secciones del periódico, como forma de analizar diferentes estrategias del uso del portugués según las variantes del discurso periodístico.

Siguiendo a Newmark (citado en BARBOSA 1990, p. 73), denominamos transferencia al macroprocedimiento que consiste en la introducción de material textual de la lengua original en el texto traducido (BARBOSA, 1990, p. 73) —en el caso de estudio, la presencia del portugués en el texto en español-, y, de acuerdo con la propuesta de Heloísa Gonçalves Barbosa (1990, p. 71), clasificamos el procedimiento descrito según las siguientes cuatro categorías:

1. Extranjerismo: inserción de términos o expresiones de la lengua original en el texto traducido que, generalmente, refieren a un concepto, técnica u objeto mencionado en el original, desconocido por los hablantes de la lengua de llegada. 
2. Extranjerismo transliterado: sustitución de un alfabeto por otro; ocurre cuando existe demasiada divergencia entre una lengua y otra o no se comparte el mismo alfabeto.

3. Extranjerismo aclimatado: adaptación del término o expresión a la lengua que toma el extranjerismo, adaptándolo a su fonología y estructura morfológica (CÂMARA JUNIOR citado en BARBOSA, 1990, p. 73).

4. Extranjerismo más explicación de su significado: empleo del extranjerismo con una explicación en forma de notas o integrada en el texto.

\section{Sobre la relación con el portugués}

De las lenguas romances, "el portugués y el español son las que mantienen mayor afinidad entre sí” (ALMEIDA FILHO, 1995, p. 14), tanto así que el par de lenguas se considera como de inteligibilidad mutua. Esta proximidad posiblemente sea una de las razones por las que su introducción en los textos en español sea admisible. Además, el portugués es una lengua que pertenece al repertorio lingüístico del Uruguay, al tiempo que circula en un espacio fronterizo que no está únicamente circunscrito al límite con Brasil. Según Behares (2007), la "frontera" se extiende en un escenario sociogeográfico más amplio, que comprende el territorio que este autor describe como "la banda norte del Río Negro hasta las nacientes del Río Uruguay en el estado [brasilero] de Río Grande del Sur, comprendiendo también los actuales departamentos uruguayos del este y del nordeste" (BEHARES, 2007, p. 99). De acuerdo con Behares (2007), la situación de bilingüismo propia de esta región parece difuminarse hacia el sur de nuestro país. Particularmente en Montevideo, la presencia del portugués parece no responder a las mismas circunstancias y relacionarse con otros aspectos puntuales (familia, estudio, turismo, trabajo, afinidad personal).

Es válido preguntarnos acerca de la presencia del portugués en los medios de comunicación, especialmente los masivos, 
concentrados en la capital del país, y a qué podría responder la presencia de esta otra lengua, que para no todos los lectores uruguayos es familiar. Debemos tener en cuenta, por cierto, que no siempre se ha reconocido de la misma manera la importancia del portugués por parte de las instituciones uruguayas. Como señala Elizaincín (1979):

\begin{abstract}
Nunca como en este año 1978, la prensa de Montevideo ha dedicado más espacio a un problema que, si bien es de notoriedad, y por lo tanto, de dominio público, suele estar reservado a la discusión de los especialistas. Me refiero al debatido asunto de la "penetración idiomática" del portugués en el territorio uruguayo. (p.5)
\end{abstract}

Si a fines de los años setenta hubo una creciente preocupación de la prensa capitalina por la "penetración" del portugués en el Uruguay (ligada a hechos históricos, geográficos y políticos), cabe cuestionarse sobre si en aquel momento era posible encontrar la presencia de esa lengua en los periódicos montevideanos. La comprobación de esta hipótesis requeriría un estudio más amplio del que aquí proponemos, pero ciertamente apunta hacia la prensa como un espacio privilegiado para el abordaje del fenómeno.

\title{
Metodología de trabajo
}

Para componer el corpus del presente análisis, seleccionamos las ediciones impresas del periódico la diaria publicadas entre el 01 de junio y el 15 de julio de 2014, considerando que el Mundial se llevó a cabo durante el período comprendido entre el 12 de junio y el 13 de julio de ese mismo año. Este medio de prensa, como se indica en su página $w^{3} b^{3}$, surgió en 2006 como diario impreso de

3 Disponible en <http://www.ladiaria.com.uy/>. 
lunes a viernes (en 2017 incorporó una edición los días sábado) y funciona por medio de suscripciones, siendo hoy el segundo periódico más vendido en Uruguay.

A efectos de localizar los extranjerismos, primeramente, realizamos una lectura completa de dichas ediciones y, al disponer de sus versiones digitales, hicimos también búsquedas por palabras clave, tales como Brasil, portugués, Mundial. Como ya fue señalado, los textos periodísticos observados no son traducciones propiamente dichas, por lo que el presente análisis procuró constatar la presencia de términos o expresiones en portugués en dichos textos y establecer, a partir de la categorización de Barbosa (1990), una posible clasificación para estos. Con el fin de determinar cuáles de las unidades lingüísticas identificadas constituyen extranjerismos tal como fueron definidos, utilizamos como criterio la aparición de dichas unidades en los siguientes diccionarios: Dicionário Houaiss da Língua Portuguesa (2009), Diccionario de la lengua española (2001) y Diccionario del español del Uruguay (2011). De esta forma, fue posible determinar qué unidades efectivamente poseen un étimo portugués y cuáles no se encuentran diccionarizadas en español y, por lo tanto, pueden considerarse extranjerismos.

Las categorías propuestas por Barbosa (1990, p. 71) utilizadas para la clasificación de los extranjerismos encontrados son las referentes a los distintos tipos de transferencia, a saber, extranjerismo, extranjerismo transliterado, extranjerismo aclimatado y extranjerismo con explicación. Al respecto, cabe señalar que la clasificación extranjerismo transliterado, por consistir en la sustitución de un alfabeto gráfico por otro (BARBOSA, 1990, p. 73), no tiene ninguna ocurrencia en el presente estudio, ya que ambas lenguas comparten el mismo alfabeto, el latino. Por otra parte, aunque Barbosa determina que en el caso del extranjerismo los términos o expresiones refieren a un concepto, técnica u objeto que es desconocido por los hablantes de la lengua de traducción (BARBOSA 1990, p. 71), en nuestro análisis aplicamos esta categoría también a casos en que se prefiere la forma en portugués a pesar de existir un término equivalente en español. Como ya advertimos 
en la introducción, el uso del portugués en los textos periodísticos estudiados responde a motivos más bien retóricos que traductivos, de todas formas, observamos en todos los casos si los vocablos o las expresiones en portugués hacían referencia a elementos o conceptos culturales propios de la cultura brasilera.

Paralelamente, observamos la naturaleza sintáctica del término o expresión y así subdividimos cada una de las categorías utilizadas en dos, según el extranjerismo se tratase de una unidad léxica o de una estructura sintagmática. También identificamos si los extranjerismos encontrados constituyen palabras del léxico común portugués o nombres propios (topónimos, antropónimos y expresiones denominativas) y si presentaban resalte tipográfico (letra itálica o comillas) que marcara su carácter foráneo. Asimismo, consignamos si las transferencias presentaban alguna desviación ortográfica o sintáctica con respecto a la norma de la lengua portuguesa, y para estos ejemplos creamos una nueva categoría excluyente: extranjerismos con desviación de la norma.

Es necesario destacar que, a los efectos de realizar el análisis cuantitativo de las expresiones encontradas, no contabilizamos los nombres propios ni los gentilicios. Si bien Aubert señala que dentro de la categoría extranjerismos los nombres propios son los de mayor ocurrencia (2003, p. 31), cuantificarlos hubiera desviado el foco de nuestro estudio, ya que no consideramos que fueran indicadores estilísticos relevantes para esta fase del trabajo. Al mismo tiempo, atendimos otras marcas del portugués que no respondían al concepto de transferencia en sentido estricto. Aunque no fueron cuantificados, consignamos los calcos, definidos según Barbosa (1990, p. 76) como aquellas estructuras sintagmáticas traducidas literalmente. Por último, para determinar el lugar de aparición de cada uno de los extranjerismos en el periódico, registramos el contexto oracional, el título del artículo, el número de página y la sección correspondientes. 


\section{Análisis del corpus}

En el relevamiento fueron sistematizados 102 recortes de las ediciones mencionadas (entre artículos, crónicas y otros géneros periodísticos) pertenecientes a las secciones Cultura, Internacional, Cartelera, Política, Deporte y Humor. También se encontraron datos en 12 de las tapas analizadas; con relación a esto último, resulta interesante notar la relevancia del uso estilístico del portugués en este medio de prensa, dado que aparece en el espacio de mayor visibilidad dentro del diario. Del total de recortes, se constata una predominancia de los extranjerismos en la sección Deportes: 57 corresponden a esa sección, 16 a Internacional, 10 a Cultura, 3 a Humor, 3 a Cartelera y 1 a Política. Sin embargo, es necesario tener en cuenta que en este conteo aún están considerados los nombres propios (antropónimos, topónimos y expresiones denominativas).

A este respecto, fueron relevados más de 540 nombres propios o expresiones denominativas. Dejando de lado lo cuantitativo, debemos mencionar que encontramos fluctuación en el uso de algunos topónimos y gentilicios: como se puede observar en los siguientes ejemplos, existen algunas variaciones en la escritura de este tipo de palabras: San Pablo - São Paulo; Maracaná - Maracanã; minero - mineiro. Decidimos discernir estos casos de otro tipo de transferencias, considerando que en el discurso de la prensa es usual mencionar antropónimos, topónimos y expresiones denominativas de lenguas extranjeras cuando se trata de coberturas internacionales.

Con relación al objetivo de este estudio, fueron consignadas un total de 94 ocurrencias de trasferencias, de las cuales 67 presentaban algún tipo de marca gráfica, en general la letra itálica o las comillas, como suelen ser destacadas en la escritura las expresiones en lengua extranjera. No obstante, entre los diferentes recortes, encontramos fluctuación en el criterio para el uso de estos recursos.

Por otra parte, del total de transferencias, 76 fueron categorizadas como extranjerismos, 9 como extranjerismos con desviación de la norma, 7 como extranjerismos con explicación y 2 como 
extranjerismos aclimatados. A continuación, ejemplificamos cada una de las categorías ${ }^{4}$.

\section{Extranjerismos}

- “cerveja, muita cerveja" (la diaria, 18/06/2014, p. 16);

- "La canarinha venció 2-1 a una Colombia” (la diaria, 07/07/2014, p. 15);

- "Y eso que me comí a los brasucas hinchando por Costa Rica en la caripela y me contaron del vai embora frente a Colombia." (la diaria, 10/07/2014, p. 16).

En estos casos, observamos la inserción de términos y expresiones propias del portugués, muita cerveja (por mucha cerveza), canarinha (forma popular utilizada en Brasil para designar a la selección nacional de fútbol), vai embora (expresión que significa "marcharse" o "irse") y brasucas (término informal para referirse a los brasileros).

2. Extranjerismos con desviación de la norma

- “dijo que ficó puto da cara, una expresión brasileña que expresa mucha rabia" (la diaria, 26/06/2014, p. 16);

- "Un himno a la amistad viajando desde Montevideo al Yuruna, un buteco que abre de madrugada en territorio brasileño" (la diaria, 09/06/2014, p. 11);

- "No sé si lo que nos contó Rafael aquella tarde de Depor tiene que ver con esta tristeza. Mais eu fiquei muito triste" (la diaria, 10/07/2014, p. 16).

En el primero de estos ejemplos encontramos la forma ficó por ficou (forma conjugada del verbo ficar, que significa 'quedar' o 'quedarse'), en el segundo buteco por boteco (expresión popular

${ }^{4}$ El destacado en negrita de los siguientes ejemplos es de nuestra autoría. 
utilizada en Brasil para referirse a establecimientos comerciales que expiden bebidas y comida de poca elaboración) y en el tercero mais por mas (conjunción adversativa cuya traducción al español podría ser mas, pero, entre otras $)^{5}$. En todos los casos, constatamos un alejamiento de la norma ortográfica del portugués, de ahí el nombre que reciben en este estudio este tipo de ejemplos.

3. Extranjerismos con explicación

- "Recordamos que frango es pollo, y que la expresión es usada para los goles vergonzosos. La referencia a Camões y Homero hacen su parte" (la diaria, 13/06/2014, p. 11);

- "sin olvidar que "sinais" también significa señales en portugués y que aparece aquí como el camino a seguir en lo que a poesía respecta." (la diaria, 10/07/20114, p. 10);

- "con un falso cachorro quente - vos sabés que es un hot dog_-" (la diaria, 16/06/2014, p. 16);

- "dijo que ficó puto da cara, una expresión brasileña que expresa mucha rabia” (la diaria, 26/06/2014, p. 16).

Esta estrategia en el texto nos parece relevante en la medida en que propone una traducción, aunque sea aproximada o de una manera informal, del término o expresión en lengua extranjera.

4. Extranjerismos aclimatados

- "Chotis, que también forma parte de nuestro folclore e integra las danzas que se bailan en las escuelas evocando tradiciones, por más que en la canción de Díaz el triángulo la vincula al forró y el baión característicos del nordeste brasileño, que la hace xote" (la diaria, 09/06/2014, p. 11).

\footnotetext{
${ }^{5}$ Este caso es un poco distinto de los anteriores, puesto que mais también es una palabra propia del portugués. A pesar de su similitud fónica en algunas variedades de esa lengua con la conjunción mas, se trata de otro elemento lingüístico bien diferente, a saber, un adverbio de cantidad, que podría ser traducido al español por más.
} 
Aquí encontramos una adaptación en español de la palabra en portugués baião (género musical y danza tradicional que se popularizó en Brasil a partir de la década de los cuarenta). También es posible encontrar este uso en páginas web, aunque no en los diccionarios consultados en este trabajo.

Sumado a lo anterior, hay otra clasificación relevante para comprender el fenómeno estudiado y supone observar el tipo de construcciones lingüísticas utilizadas en los extranjerismos, para así determinar si son de tipo léxico o sintagmático. La diferencia entre estos dos tipos de extranjerismos radica en que unos, los léxicos, se componen en cada caso de una única palabra, mientras que los sintagmáticos son unidades complejas, compuestas por más de una palabra. En estas últimas, el significado es composicional, es decir, depende del significado de las unidades léxicas que en ellas aparecen, pero también de cómo esas unidades están relacionadas sintácticamente. Del total de transferencias (94), 36 fueron categorizadas como extranjerismos sintagmáticos y las restantes 58 como extranjerismos léxicos.

A continuación, citamos algunos ejemplos de extranjerismos léxicos:

- "te recibe con un Bem-vindos" (la diaria, 23/06/2014, p. 15);

- "un lugar para comer una posta de peixe bien acompañada" (la diaria, 18/06/2014, p. 16);

- “el ánimo de los torcedores siguió en caída y el único motivo por el que muchos siguieron prestando atención a la Copa era la invasión argentina en las calles" (la diaria, 14/07/2014, p. 15).

Aquí podemos observar el uso en el primer caso de la forma en portugués bem-vindos por bienvenidos; en el segundo, peixe por pescado; y en el tercero, torcedores por hinchas.

Ahora, vayamos a los extranjerismos sintagmáticos:

- "O jogo vai começar, y de alguna manera nosotros tenemos que dejar de ser los periodistas uruguayos" (la diaria, 18/06/2014, p. 16); 
- "mientras ellas se empiezan a diversificar nos fatos da novela das oito" (la diaria, 18/06/2014, p. 16);

- "mientras ellas se empiezan a diversificar nos fatos da novela das oito, na fofoca do salão de beleza" (la diaria, 18/06/2014, p. 16);

- "me cuenta que él es de outro time" (la diaria, 18/06/2014, p. 16);

- "Mais cerveja, mais gritaria, menos jogo" (la diaria, 18/06/2014, p. 16).

Proponemos aquí una traducción al español para cada caso mencionado en el orden en que aparecen los ejemplos: "El partido va a empezar", "En los hechos de la comedia de las ocho", "en el chusmerío de la peluquería", "otro equipo", "más griterío”. Los extranjerismos sintagmáticos fueron encontrados casi en su totalidad en la sección Deporte (33 de un total de 36), las otras tres ocurrencias aparecieron en las secciones Cultura e Internacional. Destacamos que los extranjerismos pertenecientes a esta categoría ocurrieron, en su gran mayoría, en géneros textuales más literarios dentro del periódico, como la crónica, pero también en la reseña de literatura, en la sección Cultura. Es interesante señalar la extensión de algunos sintagmas en portugués, como en casos del tipo "na fofoca do salão de beleza" o "nos fatos da novela das oito", incluso fueron encontrados sintagmas de cuatro palabras o más en el mismo recorte junto con otros extranjerismos léxicos. La densidad (nos referimos a la aglutinación de varios términos y expresiones que aparecen juntos en un mismo recorte) del portugués inserto en el texto en español en el medio de comunicación estudiado es característica en los textos del tipo crónica que presentan un ribete humorístico.

En último lugar, observamos también las características semánticas de los extranjerismos relevados y distinguimos aquellos que poseen referentes culturales extralingüísticos de los que no. Seguimos aquí la conceptualización que hace Pedersen (2011, p. 43-44): se trata de la referencia por medio de alguna expresión lingüística a una entidad o proceso extralingüístico, como lugares, personas, 
instituciones, costumbres, alimentos, que solo son conocidos por la comunidad que comparte esa lengua. Del total de 94 transferencias, encontramos 70 extranjerismos que no poseen referentes culturales.

\section{Reflexiones finales}

En función de este trabajo, nos interesa destacar cómo la proximidad del portugués con el español pareciera crear una sensación de confianza en la redacción periodística, en la cual no detectamos la existencia de traductores formalmente acreditados para el uso de la lengua extranjera. Así, existiría la noción de que el español y el portugués serían casi lo mismo, creencia originada en parte por la inteligibilidad entre ambas lenguas. En consecuencia, la proyección de esta idea sobre la lengua del otro, y por ende sobre su cultura, puede ser un factor que explique en ocasiones la alta ocurrencia de inserciones de extranjerismos del portugués en la redacción en español. No obstante, sería objeto de otro estudio analizar si esos extranjerismos son comprendidos actualmente por la mayoría de lectores, tanto de Montevideo como de otras zonas del Uruguay, cuyos resultados podrían ser divergentes.

Retomando la conceptualización de la transferencia como recurso de traducción discutida al comienzo, destacamos que el uso de la lengua extranjera no responde solo a casos de falta de equivalencia. Si tenemos en cuenta que las transferencias clasificadas como extranjerismos tienen un alto número de ocurrencias respecto a las otras categorías (extranjerismos aclimatados y extranjerismos con explicación), que resultan más comprensibles para el lector, podríamos preguntarnos hasta qué punto esta abundancia de formas no traducidas presupone un conocimiento de esa lengua que, de no existir, obstaculizaría la lectura.

En cuanto a los extranjerismos con desviación de la norma, consideramos que su uso puede responder a varios motivos. No tenemos evidencia de que ese apartamiento sea ex profeso, pues los términos son incorporados al discurso y utilizados sin ninguna 
marca o comentario acerca de su desvío. Por lo tanto, presumimos que este uso responde en gran medida al desconocimiento de la lengua extranjera en cuestión (el portugués). Llama la atención entonces que, a pesar de la falta de competencia lingüística en portugués, de todos modos, se acuda a ese idioma, en ocasiones con fines humorísticos, situación que probablemente sería diferente si se tratara de una lengua no tan cercana. Es especialmente en estos casos que visualizamos la sensación de confianza a la que antes hicimos referencia.

Con respecto a los extranjerismos con explicación consideramos que, pese a que el proceso traductivo no responde a la preexistencia de un texto original en otra lengua, los extranjerismos de este tipo demuestran un acercamiento al lector, puesto que se considera el probable desconocimiento del destinatario y se ofrece una explicación para facilitar la lectura del texto.

Ya sobre el concepto de referentes culturales extralingüísticos (PEDERSEN, 2011), los extranjerismos estudiados que poseen dichos referentes representan la cuarta parte del total de transferencias encontradas. Cuando se escribe sobre el otro, muchas veces la alteridad aparece bajo la forma de este tipo de extranjerismos, que, por ejemplo, aluden a prácticas culturales que no existen en la cultura de llegada, por lo que sus hablantes no poseen expresiones para denominarlas, y es entonces cuando se acude a la lengua de partida (la extranjera) para referirse a estos fenómenos. En tales situaciones, estaríamos frente a una laguna o ausencia en la lengua de llegada, y utilizar el extranjerismo es una forma de completar ese vacío. Sin embargo, no observamos que esto sea lo que ocurre predominantemente en nuestro caso de estudio. Si un 75 por ciento de las transferencias encontradas no poseen referentes culturales, esto quiere decir que se acude a la lengua extranjera no por una necesidad, al no encontrar una equivalencia en la lengua propia, sino como una estrategia del discurso. Es en ciertos campos semánticos, tales como la comida, la música y el fútbol, que el fenómeno se expresa aún más, lo que confirma el estereotipo "Brasil de plástico", "rico, carnavalesco y a la venta" analizado por Paganotti $(2007$, p. 1). 
Finalmente, resaltamos que se debe abordar la transferencia de manera diferente según los géneros periodísticos. En este estudio, constatamos más ocurrencias en la sección Deporte, como era previsible, pero en textos que podrían clasificarse dentro del género crónica y que usan el portugués en ocasiones con fines de lograr un efecto humorístico. Sumado a ello, si tenemos en cuenta que los extranjerismos sintagmáticos aparecen casi en su totalidad en textos de este género, podemos aventurar que se trata de un espacio propicio para la experimentación con la lengua extranjera. La tradición de este género, a mitad de camino entre el periodismo y la literatura, es pródiga en el uso retórico de extranjerismos, como lo pueden demostrar las crónicas de viaje o las crónicas mundanas del modernista Rubén Darío, por ejemplo.

Las aristas expuestas hasta aquí ameritarían investigaciones de más aliento, tendientes a explicar la forma en que el español del Uruguay se ha relacionado y se relaciona con el portugués en la prensa escrita.

\section{Referencias}

Academia Nacional de Letras del Uruguay. Diccionario del español del Uruguay. Montevideo, Uruguay: Ediciones de la Banda Oriental, 2011.

Almeida Filho, J. C. Paes de. Uma metodologia específica para o ensino de línguas próximas? En J. C. Paes de Almeida Filho (org). Português para Estrangeiros: Interface com o Espanhol. Campinas, Brasil: Pontes, 1995, 13-21.

Aubert, F. As variedades de empréstimos. DELTA 19. São Paulo, 2003, 27-42.

Barbosa, H. Procedimentos técnicos da tradução: uma nova proposta. Campinas, Brasil: Pontes, 1990. 
Behares, L. E. Portugués del Uruguay y educación fronteriza. En C. Brovetto, J. Geymonat y N. Brian (comps.), Portugués del Uruguay y educación bilingüe. Montevideo: Consejo de Educación Inicial y Primaria, 2007, 99-172. Recuperado de: < http://www.cep.edu.uy/documentos/2012/publicaciones/Publi_Portu_del_ Uruguay.pdf $>$ [Consultado el 18/07/2017].

Bielsa, E. y Bassnett, S. Translation in Global News. Nueva York, NY: Routledge, 2009.

Conway, K. y Bassnett, S. (eds.). Translation in Global News. Proceedings of the conference held at the University of Warwick. Coventry, Inglaterra: University of Warwick, Centre for Translation and Comparative Cultural Studies, 2006.

Elizaincín, A. Algunas precisiones sobre los dialectos portugueses en el Uruguay. Montevideo, Uruguay: Universidad de la República, 1979.

García Yebra, V. Teoría y práctica de la traducción. Madrid, España: Gredos, 1984.

Hernández Guerrero, M. Traducción y periodismo. Berna, Suiza: Peter Lang, 2009.

Instituto Antônio Houaiss. Dicionário Houaiss da Língua Portuguesa. Rio de Janeiro, Brasil: Objetiva, 2009.

Ivir, V. Linguistic and Communicative Constraints on Borrowing and Literal Translation. En A. Beylard-Ozeroff, J. Králová y B. Moser-Mercer (eds.), Translators' Strategies and Creativity. Amsterdam, Holanda: John Benjamins, 1998, 137-144.

Paganotti, I. Imagens e estereótipos do Brasil em reportagens de correspondentes internacionais. Rumores 1(1). 2007. Recuperado de: < http://www.revistas.usp. br/Rumores/article/view/51102> [Consultado el 18/07/2017].

Pedersen, J. Subtitling Norms for Television: An Exploration Focussing on Extralinguistic Cultural References. Amsterdam, Holanda: John Benjamins, 2011. 
Quintiliano, F. M. Instituciones oratorias (traductores Rodríguez, I. y Sandier, P.). Tomo I. Madrid, España: Imprenta de Perlado Páez y Compañía, 1916a.

(1916b). Instituciones oratorias (traductores Rodríguez, I. y Sandier, P.). Tomo II. Madrid, España: Imprenta de Perlado Páez y Compañía.

Real Academia Española. Diccionario de la lengua española [en línea]. Madrid, España: Espasa, 2001. Recuperado de: < http://www.rae.es/> [Consultado el 18/07/2017].

Stetting, K. Transediting - A New Term for Coping with the Grey Area between Editing and Translating. En G. Caie (ed.), Proceedings from the Fourth Nordic Conference for English Studies. Copenhague, Dinamarca: University of Copenhagen, 1989, 371-382.

Valdeón, R. A. On the use of the term 'translation' in journalism studies. Journalism, [S.L], 14 de julio. 2017. doi: 10.1177/1464884917715945.

Vinay, J. P. y Darbelnet, J. Stylistique comparée du français et de l'anglais. París, Francia: Didier, 1958.

Recebido em: 06/04/2018

Aceito em: 05/07/2018

Publicado em setembro de 2018

Mayte Gorrostorrazo. E-mail: mayte.gorrostorrazo@fic.edu.uy

ORCID: https://orcid.org/0000-0002-2072-8707

Rosario Lázaro Igoa. E-mail: rosilazaro@gmail.com

ORCID: https://orcid.org/0000-0003-1706-8637

Leticia Lorier. E-mail: leticia.lorier@fic.edu.uy

ORCID: https://orcid.org/0000-0002-0974-9590 